\title{
Programa dE PROFISSIONALIZAÇÃO DOS MARICULTORES CATARINENSES
}

\section{Profissionalization program of the shellfishermen of Santa Catarina}

\section{Programa de profesionalización de los maricultures de Santa Catarina}

\author{
Adriano Weidner Cacciatori Marenzi ${ }^{1}$ \\ Rosemeri Carvalho Marenzi ${ }^{2}$ \\ Ana Vinholi ${ }^{3}$
}

RESUMO

\begin{abstract}
A maricultura surge no cenário brasileiro como alternativa para suprir o mercado consumidor e promover a sustentação econômica das comunidades pesqueiras. Fazendo parte dessa realidade, a Univali foi uma das instituições precursoras por meio da implantação da mitilicultura em Penha. Nesse sentido, foi desenvolvida uma série de técnicas e equipamentos apresentados em um programa de extensão para três grupos sociais: estudantes, produtores e empresários envolvidos com a atividade. Como métodos de trabalho, no mar foram instalados módulos demonstrativos para a observação e uso de equipamentos e técnicas atualizadas para o cultivo de mexilhões, e, em terra, a transferência de conhecimento se deu por meio de cursos, palestras e seminários, nas chamadas "rotas de aprendizagem". Os resultados indicam que a maior parte dos produtores, pescadores artesanais e estudantes não se envolveram no programa. Contudo, destacou-se como categoria social diferenciada a dos grandes produtores, composta por famílias de pescadores e por profissionais, que, advindos de outras atividades, tendem a adotar essas técnicas e equipamentos, agregando tecnologia e produtividade. Conclui-se que, para envolver os maricultores e promover a inclusão tecnológica na atividade, há necessidade da integração de uma equipe multidisciplinar, além dos técnicos em maricultura, com a participação de profissionais da área das ciências econômicas e sociais. Somente assim a atividade poderá desfrutar de tecnologias que promovam a qualidade de vida dos trabalhadores envolvidos e que resultem em sustentabilidade ambiental.
\end{abstract}

Palavras-chave: maricultura; extensão universitária; inclusão tecnológica.

\begin{abstract}
Aquaculture appears in the Brazilian context as an alternative to contribute to the fish market production, promoting economic sustainability to fishermen communities. As part of this context, Univali was one of the pioneer institutions, by implementing aquaculture in the municipality of "Penha/SC". Therefore, Univali developed an Informative-Outreaching Programme for three different social schemes involved within this activity: students, fishermen and managers. One of the methodologies applied was setting up trial modules in order to monitor and check out equipment; simultaneously, new techniques of mussel farming were developed. On the other hand, it was also spread to other social sectors setting up taught modules, expositions and seminars, known as "learning pathways". Results show that a major part of main producers, artisan fishermen and students did not get involved within the current programme. On the other hand, a social differentiated category formed by fishermen families and professionals was spotted as the one that concentrates the biggest producers. They used to have other activities, but their tendency is to adopt those methods and equipment described above joining technology and productivity. In conclusion, to involve
\end{abstract}

\footnotetext{
${ }_{1}$ Doutor em Ecologia. Professor da Universidade do Vale do Itajaí (Centro de Ciências Tecnológicas da Terra e do Mar). Rua Uruguai, 458, Centro, Itajaí (SC), 88302-202, (47) 3341-7500 (R: 8024), marenzi@univali.br, Programa de Pós-graduação, Pesquisa, Extensão e Cultura (Proppec).

2 Prof. ${ }^{a}$ Dr. ${ }^{a}$ da Universidade do Vale do Itajaí - Univali, Centro de Ciências Tecnológicas da Terra e do Mar.

${ }^{3}$ Mestranda em Planejamento Territorial e Desenvolvimento Socioambiental - MPPT (Udesc).
} 
shellfishermen to aquaculture methods, and therefore promote the technological inclusion, it is necessary to have a multidisciplinary team integration, and also the participation of technical staff as well as the contribution of economists and social scientists. Only this way the present activities could reach technologies that stimulate employers' life quality and bring environmental sustainability.

Keywords: aquaculture; informative-outreaching programme; technological integration.

\section{RESUMEN}

La maricultura surge en el escenario brasilero como alternativa para abastecer al mercado consumidor, y consecuentemente promover la sostenibilidad económica de las comunidades pesqueras. Formando parte de esta realidad, Univali fue una de las instituciones precursoras, gracias a la implantación de la maricultura en el municipio de "Penha/SC". En este sentido fue desarrollado un Programa Informativo-Divulgativo para tres grupos sociales: estudiantes, productores y empresarios involucrados en la actividad. Uno de los métodos de trabajo adoptados fue la instalación de módulos de prueba para la observación y uso de los equipamientos, a su vez se desarrollaron técnicas actualizadas para el cultivo de mejillones; y en tierra la trasferencia del conocimiento se formalizo mediando cursos, exposiciones y seminarios, entendidos como caminos de divulgación e aprendizaje. Los resultados indican que la mayor parte de los productores, pescadores artesanales y estudiantes no se involucraron en el programa. No obstante, se destacaron dos categoría sociales como grandes productores: las familias de pescadores; y el sector profesional, que avenidos con otras actividades, tienden a adoptar estas técnicas y equipamientos fácilmente, agregando tecnología y productividad. Finalmente, se concluye que para involucrar a los maricultores y promover la incorporación tecnológica en la actividad se necesita la integración de un equipo multidisciplinar además de técnicos maricultores, sin olvidar la participación de profesionales del área de las ciencias económicas y sociales. Únicamente de este modo, la presente actividad podrá disfrutar de tecnologías que promuevan la calidad de vida de los trabajadores involucrados, a la vez que sea medioambientalmente sostenible.

Palabras-clave: maricultura; programa informativo-divulgativo; incorporación tecnológica.

\section{Introdução}

Ao longo dos tempos, a lógica produtivista baseada na crença de inesgotabilidade dos recursos dos oceanos e mares, subjacente ao desenvolvimento acelerado na zona costeira, vem acentuando a crise da atividade pesqueira em todo o mundo. Segundo o Programa Revizee, o Brasil já apresenta, em relação aos recursos vivos marinhos, especialmente os recursos pesqueiros, um histórico de sobrepesca, de atividade predatória e insuficiência na gestão e fiscalização dos principais estoques (SEAP, 2009).

Por sua vez, o cultivo de organismos aquáticos ou aquicultura é um dos setores primários que mais se desenvolvem no cenário global da produção de alimentos e, economicamente, deverá atingir em médio prazo cifras semelhantes aos cultivos terrestres (TISDELL, 1999). Diante da situação apresentada, o mar é caracterizado por ser um importante fornecedor de alimentos no mundo e principal fonte de proteína para aproximadamente um bilhão de pessoas, daí a relevância da maricultura, especialmente a de pequeno porte (PAULILO, 2002)

Dados sinalizam um incremento significativo na aquicultura na última década no território brasileiro, atingindo um crescimento de $925 \%$ (FAO, 2008), e o cultivo de mexilhões ou mitilicultura contribui com US \$ 9,3 milhões, ou 4\% do total da produção da aquacultura nacional. Encontra no estado de Santa Catarina condições ideais e está difundido em praticamente todas as enseadas $e$ baías da costa centro-norte, com uma produção em 2004 superior a 13 mil toneladas de mexilhões Perna perna, o que representa 95\% da produção do país (OSTRENSKI; SOTO, 2008).

Atualmente, a mitilicultura no estado de Santa Catarina envolve cerca de 1.200 familias, gerando como mão de obra direta 5.000 empregos nos 12 municípios envolvidos. Os produtores estão 
reunidos em 19 associações e uma federação de maricultores, além de 5 cooperativas distribuídas em 12 Parques Aquícolas Municipais, e contam ainda com 4 unidades de beneficiamento de moluscos pertencentes às associações (EPAGRI, 2008). Considerando os volumes de produção total, os destaques em 2008 ficaram por conta dos municípios de Palhoça, com 4.898 toneladas, representando $48,32 \%$ da produção estadual, $e$ Penha, com 1.950 toneladas.

Incluída nesse cenário, Penha, situada no litoral centro-norte de Santa Catarina, iniciou as atividade de maricultura na década de 1980 (MARENZI, 1999). Contudo, somente dez anos depois, com a implantação do Núcleo de Maricultura da Universidade do Vale do Itajaí (Univali), a partir dos esforços dos extensionistas dessa instituição, a atividade passou a ser incorporada pela população local, promovendo uma "revolução" nesse município, que passou da pesca extrativista ao maior produtor nacional de mexilhões cultivados do país (MARENZI, 2002).

Penha conta atualmente com 110 maricultores associados, número que, somado aos auxiliares, chega a 400 pessoas trabalhando diretamente nos cultivos, somente no mar (EPAGRI, 2008). Além desse envolvimento direto na maricultura, a atividade tende a gerar novos empregos na produção ou reutilização de materiais diversos, como cabos e redes, bem como nas indústrias de beneficiamento.

$\mathrm{O}$ aumento da produção de mexilhões está fundamentado nos baixos custos da atividade e representa uma importante alternativa para pescadores e ex-pescadores, que vêm sendo afetados pela falta de perspectivas para a pesca tradicional e que migraram para a maricultura como atividade principal de geração de renda (OSTRENSKI; SOTO, 2008).

Todavia, a partir de 2000 , a produção no município, como em todo o estado, apresentou uma relativa estabilização, apesar do crescimento do número de maricultores, levando à redução da produtividade em relação ao esperado $e$ à neces- sidade de aumentar os esforços na transferência de tecnologia aos maricultores.

Arana (2000), ao analisar as áreas de cultivo, observou que o aspecto cultural das comunidades pesqueiras é um fator decisivo para o sucesso dessa atividade. Contudo, o cultivo de molusco no Brasil se caracteriza por ser uma atividade artesanal, com o emprego intensivo de esforço físico por causa da falta de equipamentos específicos, levando a uma baixa produtividade e lucratividade (MARENZI, 2006). Também o desconhecimento de métodos e insumos tecnológicos apropriados para a atividade, os modelos empíricos de cultivo com materiais improvisados e a depredação de estoques naturais de mexilhões para prover os cultivos conduzem à insustentabilidade no Brasil.

Para Ferreira et al. (2006), após anos de trabalho dos pesquisadores, a maricultura evoluiu e conta com soluções apropriadas para as características do produtor catarinense, permitindo suplantar seus problemas, necessitando para isso que sejam disponibilizados exemplos de sistemas e equipamentos mecânicos, em todas as etapas de produção, da fase de obtenção das sementes, plantio, manejo e colheita.

Compreendendo a íntima relação entre comunidade local e extensão, existe o reconhecimento e a valorização dos atores sociais nas ações de programas. Há evidências da terminologia de desenvolvimento local, fazendo entender que os atores são os agentes sociais e econômicos, indivíduos e instituições, que realizam ou desempenham atividades ou, então, mantêm relações num determinado território (SABOURIN, 2002).

Um programa de extensão enfatiza a participação dos diversos agentes locais na articulação das estratégias de desenvolvimento, na pretensão de melhorar a qualidade de vida da comunidade e a utilização eficiente dos recursos endógenos existentes como o arcabouço básico do que se entende como desenvolvimento local. Uma guinada nas formas de expandir a ideia de desenvolvimento, na qual a participação, qualidade de vida e recursos locais seriam os eixos da reformulada política de 
desenvolvimento. $\mathrm{O}$ apego ao lugar vem sendo também uma circunstância considerada positiva como promotora de desenvolvimento local (GOMEZ, 2001).

A compreensão por um Programa de Extensão Universitária, embasado no trabalho de Carneiro (2005), corresponde a um conjunto de ações sociocomunitárias voltadas para a produção de benefícios coletivos. Essas ações vão desde a identificação do problema até a descoberta de alternativas comunitárias de solução, tendo sempre em vista a melhoria das condições locais de vida.

Nesse sentido, o Programa de Profissionalização dos Maricultores Catarinenses teve por objetivo aumentar o grau de conhecimento técnico dos atuais e dos futuros produtores de mexilhões e demais atores envolvidos, a fim de influenciar as ações das pessoas ou instituições que se dedicam à atividade para melhorar o capital social que circula nesta.

\section{Metodologia}

Este trabalho é referente ao estudo de caso baseado nos resultados e impressões de um programa de extensão desenvolvido durante o período de 2006 a 2007, no Núcleo de Ensino da Univali, em Penha (NEP). Localizado na Enseada da Armação do Itapocoroy, Penha (SC) (2647'S - 48 36'W), o NEP dispõe de infraestrutura apropriada em terra e mar, que vem há mais de uma década sendo direcionada para esse tipo de atividade.

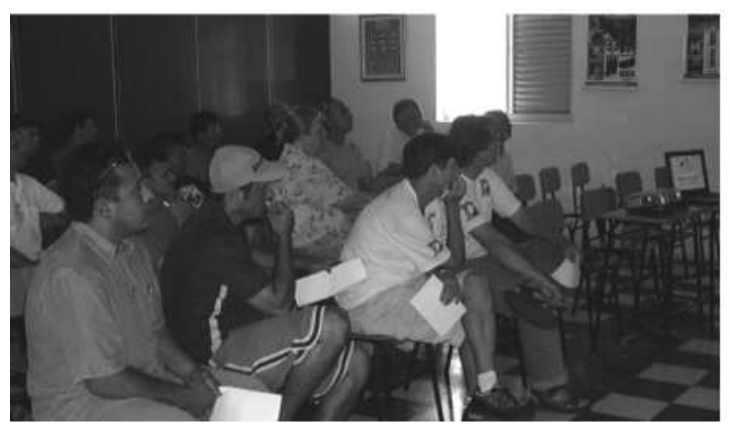

FIGURA 1 - EXPOSIÇÃO TEÓRICA NO NÚCLEO DE PENHA E DEMONSTRAÇÃO NO MAR
Este trabalho atendeu três grupos sociais: estudantes do ensino médio ou os futuros produtores, mapeados pelas unidades escolares públicas próximas; os produtores do município de Penha e outros municípios, que foram convidados por contato diretamente pelas associações de maricultores; e os empresários ligados à maricultura. Todos os participantes foram informados sobre os objetivos do programa e o agendamento das atividades segundo o grupo social. Portanto, as atividades, chamadas "rotas de aprendizagem", foram desenvolvidas de acordo com os diferentes grupos, sendo:

a) Estudantes: Durante um mês foram realizados encontros teóricos semanais com aulas expositivas sobre a maricultura, sendo enfatizados os processos de produção e aspectos biológicos dos organismos cultivados. Depois, os estudantes visitaram o cultivo dos produtores tradicionais e o modelo adotado pela Univali, onde observaram o funcionamento das máquinas de "plantio" e todo o processo necessário para o manejo adequado.

b) Produtores do parque de cultivo de moluscos, situado no município de Penha: Previamente foram realizadas reuniões sobre a possibilidade do manuseio dos equipamentos apropriados para auxiliar nos trabalhos de colheita, classificação e plantio dos mexilhões, técnicas e máquinas adaptadas ou desenvolvidas por extensionistas e técnicos da Univali, sempre ressaltando a responsabilidade da organização em forma cooperativa (Figura 1). Foi dedicado um dia por semana para atender ao trabalho diário de manejo dos cultivos.

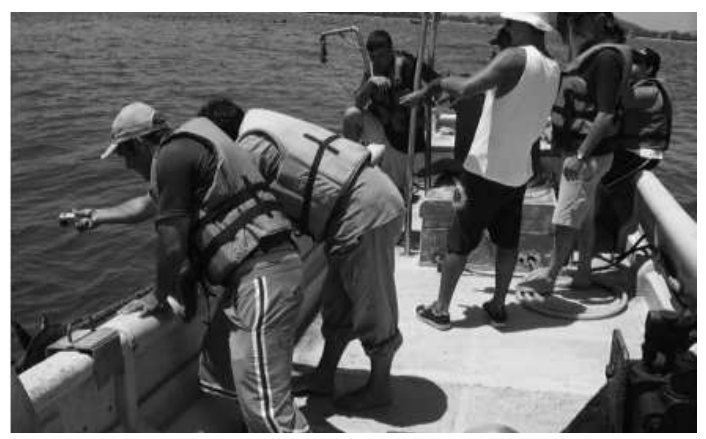


c) Produtores dos demais municípios de Penha e empresários: Foi realizado um encontro denominado "Dia-de-Mar", para apresentação e demonstração de novos produtos, técnicas e equipamentos da Univali e de outros produtores e empresas. Técnica esta semelhante às efetuadas pelas indústrias ligadas à agricultura nos "Dias-de-Campo", promovendo o contato direto com os equipamentos, demonstrando o funcionamento, seu manuseio e finalizando em terra uma discussão com todo o grupo.

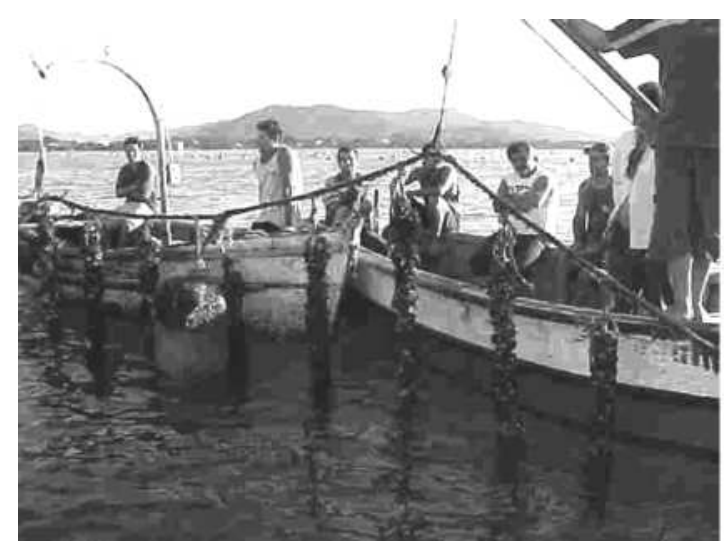

Assim, pode-se demonstrar in loco aos estudantes, produtores e empresários, a eficiência e a facilidade da realização de funções. Dentre elas: a suspensão de redes de mexilhões com guincho apropriado sem limitação da força muscular, a individualização de mexilhões com eficientes equipamentos mecânicos, a produtiva confecção das redes de cultivo de forma padronizada, como também a seleção e limpeza da produção sem comprometer a integridade física do produtor pelo esforço e repetição de movimentos (Figura 2).

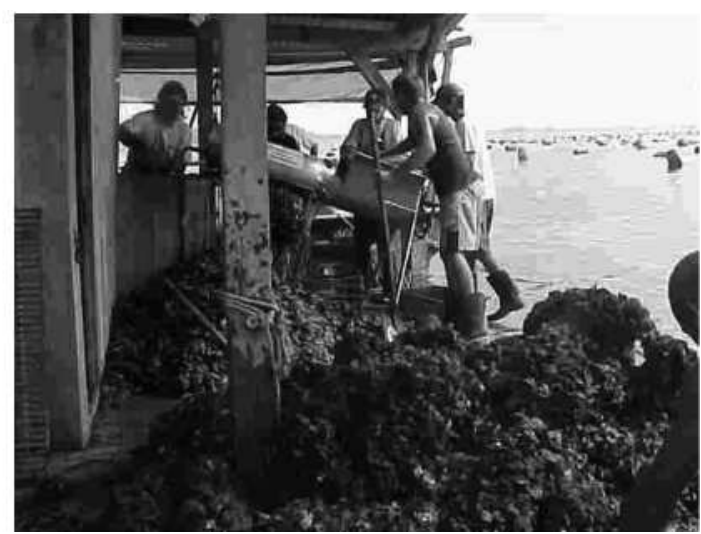

FIGURA 2 - ATIVIDADES PRÁTICAS NO PARQUE DE CULTIVO COM OS EQUIPAMENTOS E TECNOLOGIAS ATUALIZADAS

Salienta-se que, além das questões voltadas à produção, o programa implantou coletores artificiais de larvas (Figura 3) e demonstrou a viabilidade do uso destes pelos maricultores, procurando suprimir a necessidade dos produtores de recorrer aos bancos naturais de mexilhões para obter as sementes para serem cultivadas, levando às desastrosas consequências ambientais.
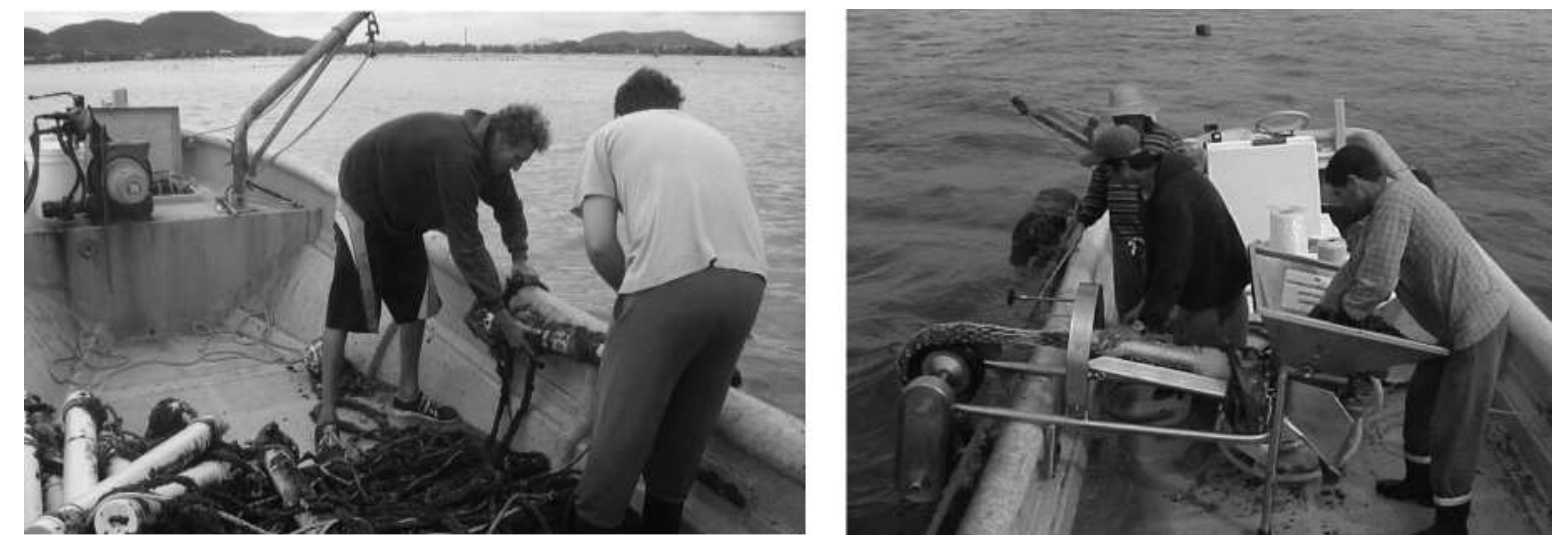

FIGURA 3 - DEMONSTRAÇÃO DE TIPOS DE COLETORES ARTIFICIAIS DE MEXILHÕES E O RESULTADO DE SEU PLANTIO EM SISTEMA CONTÍNUO 
Para a avaliação do programa, realizouse um levantamento numérico dos estudantes, produtores e empresas atendidos ao longo de um ano de atividades e confrontaram-se esses números com os que permaneciam vinculados de alguma forma ao programa ao final do período.

No mar, avaliou-se o número de solicitações de uso dos equipamentos e as alterações observadas nos barcos, nas estruturas de cultivo e técnicas empregadas nas atividades diárias dos maricultores do parque aquícola de Penha, que contribuíram para melhorar a produtividade e a qualidade de vida dos produtores.

\section{Resultado e discussão}

Ficou evidente que a Univali, com a experiência, tecnologia e materiais desenvolvidos em anos de trabalho na maricultura, tem condições de ser referência nacional nesse tipo de ação de extensão para as comunidades, desde que haja interesse dos produtores. Contudo, é no âmbito social que estão os maiores problemas da atividade, fato evidenciado nas reuniões executadas, quando, apesar de convites diretos $e$ indiretos, bem como por meio de "corpo-a-corpo" nas praias do município de Penha, dos 112 maricultores filiados à associação e cooperativa local, apenas $20 \%$ permaneceram durante todo o período das reuniões e somente $4 \%$ demonstraram entusiasmo pelo tema.

A falta de persistência dos produtores se deve, segundo seus testemunhos, ao fato de que a atividade não produz suficiente renda econômica para que possam investir em equipamentos e materiais além dos que estão utilizando, como cabos e redes reutilizadas de outras atividades.

A criação de empregos é fato importante, pois somente na cidade de Penha (SC),
500 alunos se formaram no ensino médio na escola atendida pelo projeto em 2006. Segundo o diretor da escola, nestsa mesma época foram oferecidos 9 empregos pelo Sine local (comunicação pessoal). No entanto, a descrença de que a maricultura possa vir a se tornar uma atividade realmente lucrativa e a atual semelhança com a pesca artesanal, no esforço físico, exigência de dedicação e insegurança financeira, se refletem na relutância dos jovens da região em aderir ao cultivo de moluscos.

Por essa razão, apesar de todo o potencial da atividade em absorver novos maricultores, dos 120 estudantes que se propuseram inicialmente a acompanhar as atividades do programa, e mesmo este tendo sido divulgado pessoalmente nas escolas e oferecido de forma gratuita, menos de $10 \%$ dos alunos compareceram nos encontros $e$ apenas $5 \%$ (seis estudantes) participaram por um período superior a um mês (Quadro 1).

QUADRO 1 - PÚBLICO ENVOLVIDO DIRETAMENTE COM O PROGRAMA

\begin{tabular}{|c|c|c|}
\hline Estudantes & Maricultores & Empresas \\
\hline 120 & 130 & 18 \\
\hline
\end{tabular}

Dessa forma, a formação profissional em maricultura deve afastar futuros maricultores de uma comparação com os pescadores artesanais, preparando-os para um mercado de trabalho numa área que tende a se desenvolver rapidamente, com o uso de metodologia e equipamentos específicos, tornando a atividade do cultivo de moluscos uma atividade com reais perspectivas. Como salienta Diegues (1995) em seu artigo sobre as realidades e falácias em torno dos pescadores artesanais, existe a necessidade de'marginal' ou peça de folclore."

Apesar da reduzida presença dos maricultores, a atividade que obteve maior destaque dentre aquelas desenvolvidas pelo programa foi o "Dia-de-Mar", com a participação das empresas de insumo e assistência técnica para a maricultura do estado, apresentando seus produtos $e$ socializando suas perspectivas para o setor em 
um clima de esperança e boas expectativas. Contudo, apesar de haver um grupo diferenciado de produtores com maior poder de investimento, de forma geral o projeto evidenciou a falta de interesse da maioria dos produtores em reverter o atual quadro da maricultura catarinense.

A interação da universidade com os maricultores e a comunidade envolvida é essencial, uma vez que há dificuldade de convencer os produtores a aderir ao programa, consequentemente de usar novas tecnologias a fim de desenvolver técnicas que melhorem a produção de mexilhões e suas condições de vida. No entanto, para atingir tais objetivos, fazem-se necessários a internalização e o esclarecimento de todos os envolvidos no programa sobre "território", conceito teórico que alerta para as considerações políticas e históricas de uma comunidade. Como categoria conceitual, território designa uma trama de relações com raízes históricas, configurações políticas e identidades que desempenham um papel ainda pouco conhecido no próprio desenvolvimento econômico (ABRAMOVAY, 1998).

Complementa Cirad-Sar (1996), informando que o território não é um simples suporte físico das atividades econômicas nem um quadro de localização dos agentes - ele é um espaço construído histórica e socialmente, no qual a eficiência das atividades econômicas é intensamente condicionada pelos laços de proximidade e pelo fato de pertencer a esse espaço. O território é, então, um resultado, e não um dado. Por isso, fala-se de "construção de territórios" a partir de estratégias dos atores envolvidos e de mecanismos de aprendizagem coletiva, quer dizer, a aquisição de conhecimentos, de informações comuns, por meio da prática ou da experiência coletiva.

Esses resultados indicam que o problema atual da maricultura de moluscos em Santa Catarina não são as questões técnicas, e sim sociais, cabendo à equipe multidisciplinar pensar em conjunto com os diversos atores sociais (coparticipação) quais projetos e tarefas serão re- alizados no programa. Ao pesquisador, algumas dicas da antropologia na imersão na comunidade (trabalho de campo): buscar perceber a realidade a partir do olhar do outro, ouvir/ver, ler nas entrelinhas, compreender as tramas entre os espaços públicos e privados e, por fim, saber identificar as lideranças "invisíveis" e reconhecidas. Compreender a história da comunidade é peça-chave para a adesão/implementação do programa. Nesse sentido, a história não é mera sucessão de fatos no tempo, não é o progresso das ideias, mas o modo como homens determinados criam os meios e as formas de sua existência social, que é econômica, política e cultural; a história é práxis (no grego, práxis significa um modo de agir no qual o agente, sua ação e o produto de sua ação são termos intrinsecamente ligados $e$ dependentes uns dos outros, não sendo possível separá-los). Nessa perspectiva, a história é o real, e o real é o movimento incessante pelo qual os homens, em condições nem sempre escolhidas por eles, instauram um modo de sociabilidade $e$ procuram fixá-lo em instituições (família, condições de trabalho, relações políticas, instituições religiosas, tipos de educação, formas de arte, transmissão de costumes, língua, etc.) (CHAUÍ, 1980).

Perante a ausência dos maricultores, mesmo com as constantes estratégias de convencimento, por razões de contrapartida positiva, o programa passou a dedicar maior atenção aos grandes produtores de Penha, pois parecem perceber a maricultura como uma atividade de longo prazo e, por isso, necessitam de atenção no aperfeiçoamento tecnológico de suas atividades.

Esse público merece ações colaboradoras das instituições universitárias tanto quanto os demais maricultores, mas, à medida que este serviço se torne constante e gere lucros privados, será necessária uma prestação de serviços, e não mais extensão.

Com o desinteresse dos produtores em implementar tecnologias específicas para o 
cultivo de moluscos com o uso de metodologia e equipamentos específicos, não será possível reverter a baixa produtividade e qualidade do produto final, o que se torna uma barreira para que a atividade seja competitiva perante os produtores internacionais, especialmente o Chile, que a cada ano dobra sua produção de mexilhões. Também o esforço físico e a ausência de empregos formais tenderão a tornar essa categoria um problema de saúde pública e de previdência social para o estado. Os aspectos científicos da aquicultura são suficientemente avançados para propor ações preventivas $e$ determinar que as tecnologias de cultivo sejam aplicadas para obter uma aquicultura racional $e$ sustentável (BOYD; SCHMITTOU, 1999).

O Plano de Desenvolvimento Sustentável para a Pesca e Aquicultura, segundo o Ministério da Pesca (2009), estabelece que:

é preciso aprofundar o processo de valorização da pesca e da cultura das populações tradicionais, assegurando os direitos dessas populações e considerando o reconhecimento de suas diversidades culturais. A aqüicultura familiar se coloca também como uma alternativa $e$ uma oportunidade de emancipação $e$ promoção da autonomia de milhares de trabalhadores, gerando emprego, aumentando a renda e promovendo a qualidade de vida (p.10).

Portanto, este programa procurou contribuir para essa realidade, profissionalizando a atividade, e não só revelou resultados preocupantes, mas possibilitou oferecer opções menos impactantes, racionalizando o uso de sementes ou mexilhões jovens pelos produtores, e foi possível observar sua mudança de comportamento. Isso permitirá reduzir os atuais índices de mortalidade nos cultivos e minimizar a depredação dos bancos naturais nos costões rochosos. Para Folke e Kautsky (1992), a real busca da aquicultura moderna será redirecionar-se para um desenvolvimento sem prejuízo para o meio ambiente, integrando os cultivos aos processos e funções do meio.

\section{Conclusões}

As atividades desenvolvidas neste projeto foram realizadas utilizando maquinário apropriado para o cultivo de moluscos, tornando a área de cultivo e equipamentos da Univali em Penha um módulo demonstrativo e propiciando exemplos a serem seguidos pela comunidade de maricultores.

Urge a disseminação de equipamentos adequados à atividade, ou seja, a mecanização de diversas etapas da produção, pois, apesar dos avanços tecnológicos dos produtores com o uso de guinchos e embarcações adequadas, o sistema de cultivo ainda se caracteriza como uma atividade artesanal de uso extensivo de força física.

A interação da universidade com os maricultores é essencial, uma vez que há dificuldade de convencimento e de estímulo aos produtores para aderir de forma voluntária ao uso de novas tecnologias.

Um dos pontos positivos do projeto foi a racionalização no uso de sementes ou mexilhões jovens, fato que pode estar ligado mais à dificuldade e aos custos de obtenção destas do que a uma conscientização da sustentabilidade da atividade.

A extensão deve levar à libertação (no sentido amplo da palavra) dos participantes. Caso não ocorra real mudança de comportamento dos produtores, o investimento de recursos econômicos pelo governo pode ser caracterizado por clientelismo.

A participação mais efetiva de empresários, apesar de merecedores, pode se caracterizar 
como um favorecimento, se houver tendência à centralização da produção. Entretanto, pode também ser o caminho dessa atividade, caso não ocorra mudança no hábito dos atuais maricultores em relação aos problemas da atividade.

\section{REFERÊNCIAS}

ABRAMOVAY, R. Bases para a formulação de política brasileira de desenvolvimento rural: agricultura familiar e desenvolvimento territorial. Brasília: Ipea, 1998. 25 p. (Convênio Fipe/Ipea). Relatório final.

ARANA, L. A. V. Modo de apropriação e gestão patrimonial de recursos costeiros. Tese - Departamento de Ciências Sociais, Universidade Federal de Santa Catarina, 2000. $220 \mathrm{p}$.

BOYD, C. E.; SCHMITTOU, H. R. Achievement of sustainable aquaculture through environmental management. Aquaculture: Economics \& Management, v. 3, n. 1, p. 59-69, 1999.

CARNEIRO, M. A. Extensão universitária - versão e reflexões. Rio de Janeiro, João Pessoa: Presença/UFPB, 1985. $156 \mathrm{p}$.

CHAUÍ, M. O que é ideologia. São Paulo: Brasiliense, 1980. (Col. Primeiros Passos)

CIRAD-SAR. Systemes agro-alimentaires localisé: organisations, innovations et developpement local. Montpellier: CIRAD-SAR, 1996. (CIRAD-SAR, 134-96)

DIEGUES, A. C. Povos e mares - leituras em sócioantropologia marítima. Nupaub-USP, 1995.

EPAGRI. Secretaria da Agricultura e Abastecimento do Estado de Santa Catarina. Boletim Informativo anual. Florianópolis, 2008. 17 p.

FAO - Food Agriculture Organization The State of World's Fisheries and Aquaculture 2008. FAO Information Division. Rome, Italy, 2008.

FERREIRA, J. F. et al. Coletores de sementes. Panorama da Aqüicultura, v. 96, p. 43-48, 2006.

FOLKE, C.; KAUTSKY, N. Aquaculture with its environment: prospects for sustainability. Ocean \& Coastal Management, n. 17, p. 5-24, 2003.

GOMEZ J. M. A questão do desenvolvimento nas reformulações da política agrária brasileira: reflexões iniciais. Pegada eletrônica, Maringá, v. 2, n. 2, 2001.
MARENZI, A. W. C. Development of mussels Perna perna (L, 1758) (mollusca-Bivalvia) in Culture in South of Braziliam. Journal of Coastal Research, v. SI, p. 1102-1105, 2006.

. Uso de mecanização do cultivo de mexilhões. Revista do Setor de Ciências Agrárias, Curitiba, v. 17, n. 1-2, p. 155-163,1999.

; BRANCO, J. O. Cultivo de mexilhões Perna perna no município de Penha, SC. In: BRANCO, J. B.; MARENZI, A. W. C. (Orgs.). Bases ecológicas para um desenvolvimento sustentável. 1. ed. Itajaí: Univali, 2006. v. 1 , p. $227-244$.

Pesca e maricultura. In: FARIAS, Wilson (Org.). Município de Penha. Florianópolis: 2002.

OSTRENSKY, A.; SOTO, J. R. B. D. Aqüicultura no Brasil: o desafio é crescer. Brasília, 2008. 276 p.

PAULILO, M. I. S. Maricultura e território em Santa Catarina - Brasil. Cadernos de Pesquisa, PPGSP - UFSC, Florianópolis, n. 31, ago. 2002.

SABOURIN, E. Desenvolvimento territorial e abordagem territorial - conceitos, estratégias e atores. In: TEIXEIRA, O. A. (Eds.). Planejamento e desenvolvimento dos territórios rurais - conceitos, controvérsias, experiências. Brasília: Embrapa Informação Tecnológica, 2002. p. 21-37.

SEAP - Secretaria Especial de Aqüicultura e Pesca. Cartilha: mais pesca e aquicultura: plano de desenvolvimento sustentável. Brasília, 2009.

TISDELL, C. Overview of environmental and sustainability issues in aquaculture. Aquaculture Economics \& Management, v. 3, n. 1, p. 1-5, 1999.

Texto recebido em 20 de março de 2009. Texto aprovado em 22 de setembro de 2009. 